\title{
Die neue SÄZ-Homepage ist live!
}

\author{
Übersichtlich, benutzerorientiert, modern und dynamisch. Mit diesen Attributen \\ lässt sich der neue Internetauftritt der Schweizerischen Ärztezeitung auf den Punkt \\ bringen. Neben einer optimierten Präsentation der Informationen rund um das \\ Schweizer Gesundheitswesen wird dank neuen Tools der Meinungsaustausch inner- \\ halb der Leserschaft auf attraktive Art vereinfacht und angeregt.
}

Matthias Scholer

mscholer[at]emh.ch
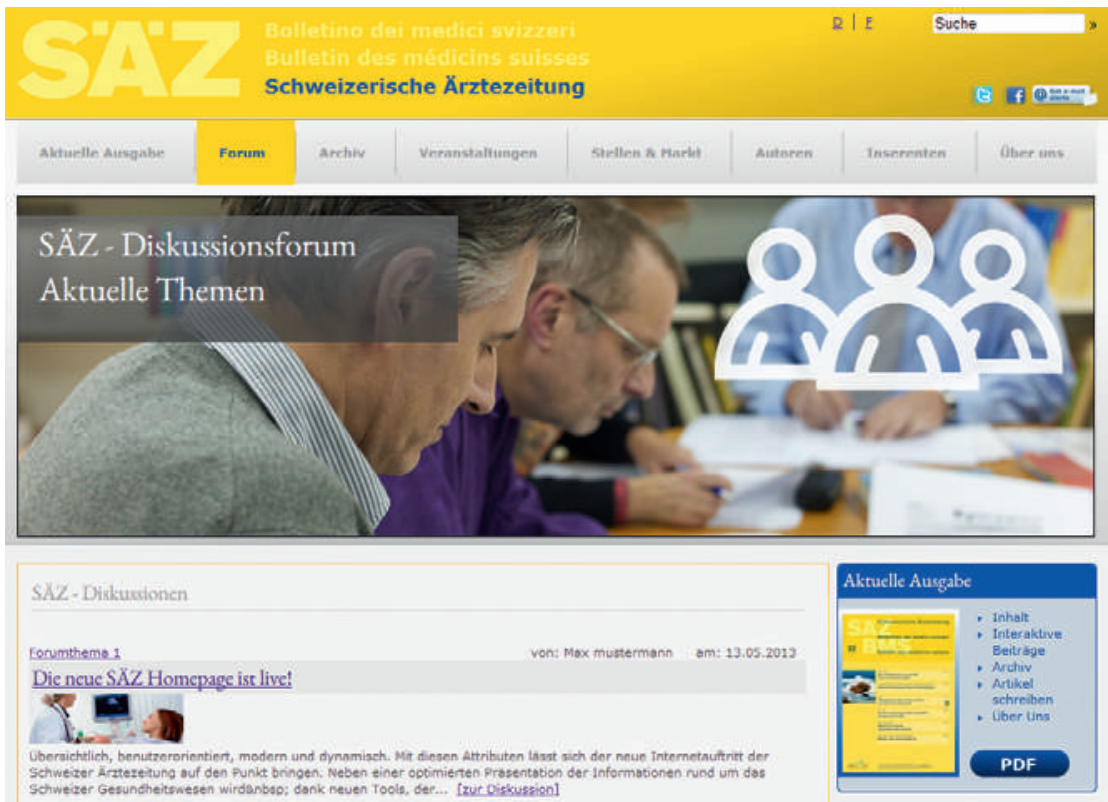

Abbildung 1

Im neuen Forum können aktuelle Themen interaktiv diskutiert werden.

Rund 2000 User besuchen täglich die Homepage der Schweizerischen Ärztezeitung, Tendenz steigend. Auch wenn die Printausgabe das primäre Kommunikationsmittel der Schweizer Ärzteschaft ist und bleibt, darf der Stellenwert elektronischer Medien als Informationsquelle und als Plattform für einen interaktiven Meinungsaustausch nicht unterschätzt werden. In diesen Bereichen bestand bei der OnlineAusgabe der SÄZ Nachholbedarf. Mit der Neukonzipierung konnte diese Lücke nun geschlossen werden.

\section{Neues Layout und optimierte Struktur}

Die Leserschaft hat nun die Möglichkeit, sich online an der Diskussion ausgewählter Themen zu beteiligen. Für diesen interaktiven Dialog wurde der Menüpunkt «Forum» eingerichtet (Abb. 1).

Das Redaktionsteam greift dafür monatlich mindestens ein Thema aus den Bereichen Wissenschaft, Wirtschaft und Politik auf, das aufgrund seiner 


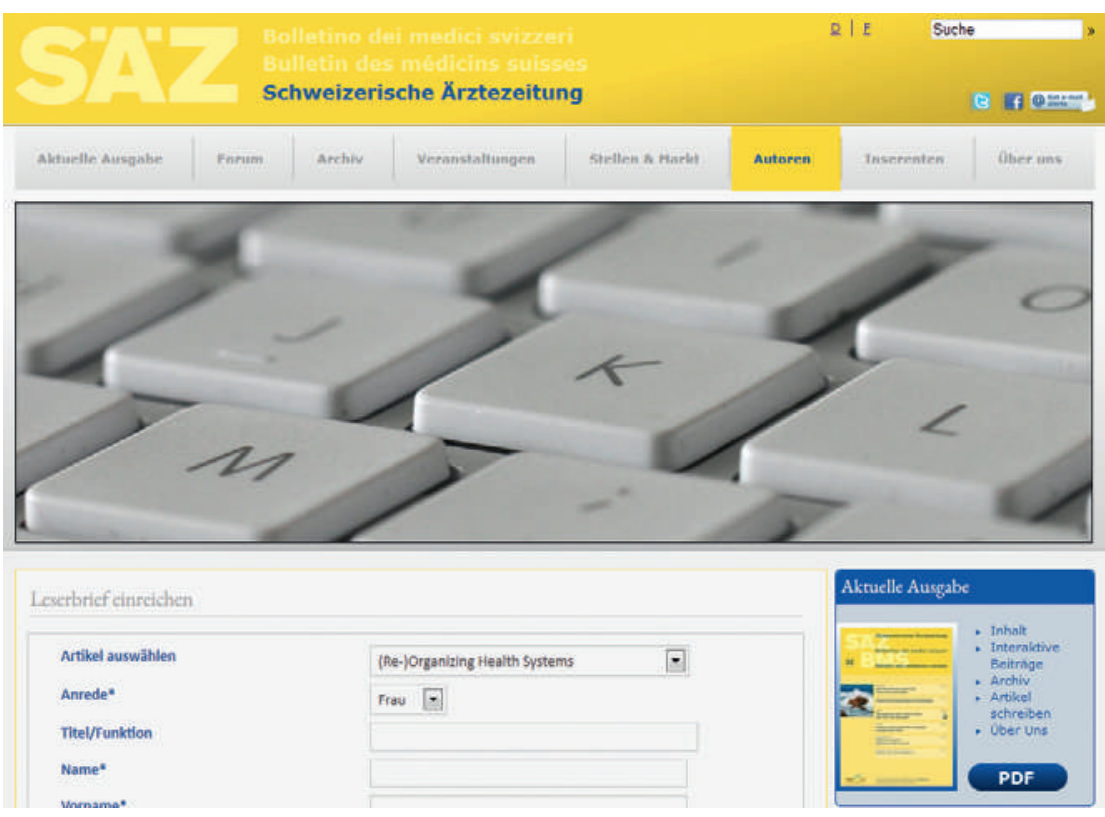

Abbildung 3

Die neue Eingabemaske vereinfacht die Einreichung von Leserbriefen.

ein nachträglicher, zeitraubender Mailverkehr zwischen den Verfassern und der Redaktion auf ein Minimum reduziert und die Leserbriefe können dadurch rascher und zeitnaher publiziert werden.

Zum Ausbau der Benutzerfreundlichkeit gehört zudem auch die vereinfachte Einreichung von Inseraten und Veranstaltungshinweisen, sowie die Hinterlegung eines individuellen Profils für Stellensuchende.

\section{Aktualität und Multimedialität}

Damit sich die SÄZ-Homepage zu einer attraktiven und zeitgemässen Informationsplattform entwickeln kann, erscheinen neu ausgewählte Beiträge und Neuigkeiten ausschliesslich online. Dies betrifft insbesondere Themen und Meldungen, die bis zu einer Veröffentlichung in der gedruckten Zeitschrift zu stark an Aktualität einbüssen würden. Solche Informationen werden künftig aus einem Mix verschiedener Formate angeboten - von Texten über Videobeiträge bis hin zu kommentierten Bildstrecken. Sind dabei Eigenproduktionen nicht möglich bzw. zu aufwendig, werden die Beiträge anderer Medien auf der SÄZ-Homepage eingebettet oder die User auf die entsprechenden Quellen verwiesen. Damit können sich die Nutzerinnen und Nutzer jederzeit und mit wenigen Mausklicks einen umfassenden Überblick über Neuigkeiten im schweizerischen Gesundheitswesen verschaffen, ohne die Informationen im Netz mühsam zusammenzusuchen.

Der Schweizerische Ärzteverlag EMH ist überzeugt, mit diesen Anpassungen einen wichtigen und richtigen Schritt in die Zukunft zu machen und damit die Schweizerische Ärztezeitung als zentrales Kommunikationsmittel der Ärzteschaft nachhaltig zu verankern - sowohl im Print- als auch im OnlineBereich. Dabei legen wir grossen Wert darauf, die verschiedenen Bedürfnisse und Gewohnheiten der treuen Leserschaft zu respektieren und abzudecken.

Und wem die verstärkte Onlinepräsenz noch zu wenig weit geht, darf sich schon bald über eine mobile App der SÄZ freuen.

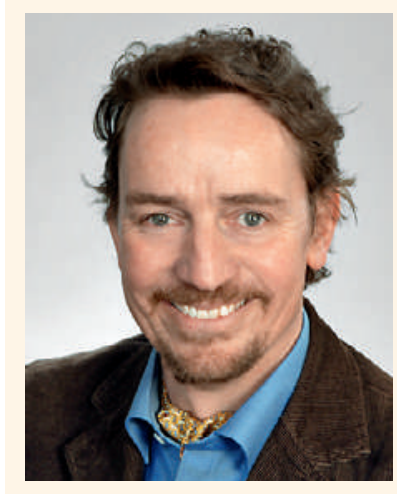

\section{Neuer Online-Redaktor}

Matthias Scholer leitete die Neukonzipierung der SÄZ-Homepage. Seit diesem Mai betreut er sie, in enger Zusammenarbeit mit dem übrigen Redaktionsteam, auch redaktionell. Matthias Scholer studierte Veterinärmedizin an der Universität Bern. Nach erfolgreicher Promotion arbeitete er im Marketing einer Tochtergesellschaft des damaligen «Schweizer Serum- und Impfinstituts». Nach einer Ausbildung im Wissenschaftsjournalismus war Matthias Scholer unter anderem als Redaktor bei der «Maurice E. Müller Stiftung» und der Zeitschrift ManagedCare tätig. Neben seiner Tätigkeit bei EMH leitet er den CAS Fachjournalismus an der Schweizer Journalistenschule MAZ und verfasst für Publikumsmedien regelmässig Berichte über wissenschaftliche Themen. 